\title{
Synergic Effect and Kinetic Mechanisms for Co-Pyrolysis of Empty Fruit Bunch and Palm Oil Sludge
}

(Date Received: 25.04.2017/Date Accepted: 27.07.2017)

\author{
Yen Yee Chonga, Suchithra Thangalazhy-Gopakumar ${ }^{\mathrm{a}, 1}$, Suyin Gan ${ }^{\mathrm{a}}$, Hoon Kiat Ng', Lai Yee Lee ${ }^{\mathrm{a}}$ \\ ${ }^{a}$ Department of Chemical and Environmental Engineering, Faculty of Engineering, \\ University of Nottingham Malaysia Campus, Jalan Broga, Semenyih 43500, Selangor Darul Ehsan, Malaysia. \\ ${ }^{b}$ Department of Mechanical, Materials and Manufacturing Engineering, Faculty of Engineering, \\ University of Nottingham Malaysia Campus, Jalan Broga, Semenyih 43500, Selangor Darul Ehsan, Malaysia.
}

\begin{abstract}
The thermochemical behaviour of Co-Pyrolysis between Empty Fruit Bunches (EFB) and Palm Oil Mill Effluent (POME) sludge were studied using Thermogravimetric Analysis (TGA). EFB, POME sludge, and their blends (EFB : POME sludge of 100:0, 90:10, 75:25, 50:50, 25:75, and 0:100) were studied at different heating rates $(5,10,20,30$, and 40 $\mathrm{C} / \mathrm{min})$ with nitrogen $\left(\mathrm{N}_{2}\right)$ purge of $20 \mathrm{ml} / \mathrm{min}$ to simulate pyrolysis conditions. All the samples experienced three pyrolysis stages and for each stage, the mechanisms responsible were determined. During co-pyrolysis, a positive synergistic effect was observed in the experiments, which is a favourable finding. With the increase in POME sludge percentage in the blends, the activation energy for the main decomposition stage (Stage 2) decreased from $89.33 \mathrm{~kJ} / \mathrm{mol}$ to $63.47 \mathrm{~kJ} / \mathrm{mol}$, when the kinetic model was first order reaction ( $F 1)$.

Keywords: Co-Pyrolysis, EFB, TGA, POME Sludge, Synergistic Effect.
\end{abstract}

\subsection{INTRODUCTION}

Global energy demand has been on the rise and carbon dioxide $\left(\mathrm{CO}_{2}\right)$ emissions are commonly associated with energy production, which contributes to climate change. Concerns on the effects of fossil fuel emissions on the environment and energy security have been raised. Among renewable energy sources, biomass shows high potential in terms of feed flexibility and abundance. Malaysia is known as the largest exporter of palm oil, and so, large amount of palm waste are being produced simultaneously. A review on the utilization of the palm waste in the production of biomass energy was conducted [1].

Liquid fuel is the energy source that is consumed most in the world. Thus, finding a potential substitute for liquid fuels is important. This study takes interest in fast pyrolysis, a thermochemical conversion method of biomass to obtain liquid fuel, known as bio-oil, due to the high oil yield and high energy density compared to virgin biomass. Abdullah et al., characterized the bio-oil derived from EFB and obtained a low $\mathrm{pH}$ of between 2 and 3 [2]. Having a high acidity causes the bio-oil to be corrosive and not suitable to be directly used as direct fuel. Bio-oil derived from POME sludge has a high $\mathrm{pH}$ of about 9.4, signifying that the bio-oil is alkaline in nature. Thus, Thangalazhy-Gopakumar et al., suggested the co-pyrolysis of lignocellulosic biomass and sludge in order to achieve a neutralized bio-oil [3].

Co-pyrolysis of biomass is one of the potential options to improve the quality of bio-fuel. Due to the differences in chemical and physical properties of different biomass, a different thermal reactivity may occur during co-pyrolysis [4].
A positive synergistic effect was observed in the co-pyrolysis of oil-palm solid wastes and paper sludge, contributing to an increase in both gas and liquid products, but decrease in char production [5]. This effect was favourable in achieving a higher liquid yield. However, co-pyrolysis between sewage sludge and pine sawdust did not show significant synergistic effect upon thermal degradation; an inhibitive effect was observed by Mu et al., in the co-pyrolysis of petrochemical wastewater sludge with lignite, indicated by a negative synergistic effect [4], [6].

Biomass exhibits different behaviours in thermal process. The characterisation of EFB and POME have been done individually. However, the study on the reactivity and kinetics of the co-pyrolysis of EFB and POME have yet to be done. This study aims to investigate the thermal behaviour of the copyrolysis of EFB and POME upon fast pyrolysis.

\subsection{MATERIALS AND METHODS}

\subsection{Feedstock Characterization}

The feedstocks used in this work were palm Empty Fruit Bunches (EFB) and treated Palm Oil Mill Effluent (POME) sludge. The samples were collected from Seri Ulu Langat Palm Oil Mill Sdn. Bhd, Dengkil, Selangor (Malaysia). EFB was dried in an oven at $75^{\circ} \mathrm{C}$ for $16 \mathrm{~h}$. Dried sludge, which was ready to compost in soil was collected and further sun dried for 3 days. The samples were then grounded to less than $2 \mathrm{~mm}$ in particle size. The feedstock properties are presented in Table 1 . The moisture content was 


\section{SYNERGIC EFFECT AND KINETIC MECHANISMS FOR CO-PYROLYSIS OF \\ EMPTY FRUIT BUNCH AND PALM OIL SLUDGE}

calculated as weight differences after being placed in the oven at $103^{\circ} \mathrm{C}$ for 16 hours. The ash content of the sample was determined per ASTM E 1755 standard. Higher heating values (HHV) of both EFB and POME sludge were measured using Parr 6100 bomb calorimeter. Different blends at different EFB to POME sludge ratios were prepared by mixing (100:0 90:10, 75:25, 50:50, 25:75, and 0:100).

Table 1: Ultimate and Proximate Analyses and HHV of EFB and POME Sludge

\begin{tabular}{|l|c|c|c|}
\hline \multirow{2}{*}{ SAMPLE } & \multicolumn{2}{|c}{ PROXIMATE ANALYSIS } & \multirow{2}{*}{ HHV (MJ/kg) } \\
\cline { 2 - 3 } & Ash (\%) & Moisture (\%) & \\
\hline EFB & $1.42 \pm 0.17$ & $5.10 \pm 0.77$ & $18.24 \pm 0.11$ \\
\hline POME & $24.17 \pm 0.28$ & $13.60 \pm 0.12$ & $14.52 \pm 0.01$ \\
\hline
\end{tabular}

\subsection{Mathematic Background}

Thermogravimetric analysis was carried out in programmable TGA DSC 1 Mettler Toledo to examine the decomposition behaviour of biomass upon pyrolysis. The different EFB to POME sludge ratios were taken for co-pyrolysis studies. The samples were heated at a heating rate of $5,10,20,30 \& 40^{\circ} \mathrm{C} /$ min with nitrogen $\left(\mathrm{N}_{2}\right)$ purge of $20 \mathrm{ml} / \mathrm{min}$. In each experimental run, approximately $10 \mathrm{mg}$ of biomass was heated from room temperature to $900^{\circ} \mathrm{C}$, and held at that temperature for 10 mins. The experiments were duplicated to ensure the reproducibility of results.

\subsubsection{Interaction}

To study the existence of interaction between the EFB and POME sludge blends upon pyrolysis, the theoretical values for TG and DTG curves of the blends were calculated. Eqn. (1) shows the calculation to obtain the values by adding the decomposition curves of each individual component:

$W=x_{E F B} \cdot W_{E F B}+x_{\text {sludge }} \cdot W_{\text {sludge }}$

where, $W$ is the theoretical TG or DTG values of the blends; $W_{E F B}$ and $W_{\text {sludge }}$ are experimental TG and DTG values of EFB and POME, respectively; $x_{E F B}$ and $x_{\text {sludge }}$ are mass percentages of $\mathrm{EFB}$ and POME in the blends.

\subsubsection{Kinetic Model}

Kinetic analysis of EFB, POME sludge, and their blends were carried out to obtain the kinetic triplets (activation energy (E), apparent pre-exponential factor (A), kinetic model $f(a)$ ).

The conversion degree, $\alpha$ has been defined as the mass fraction of decomposed solid:

$\alpha=\frac{m_{o}-m}{m_{o}-m_{f}}$

where $m_{o}, m$, and $m_{f}$ are the initial, instantaneous, and final masses of the solids respectively.

In non-isothermal experiments, the rate of solid degradation can be written as:

$\frac{d \alpha}{d t}=k f(\alpha)$

where $\mathrm{k}$ is the temperature-dependant rate constant and $f(\alpha)$ is a function of conversion that varies according to the reaction model. The reaction constant, $k$ can be expressed by Arrhenius equation

$k=A \exp \left(-\frac{E}{R T}\right)$

where $A$ is the pre-exponential factor, $E$ is the activation energy, $R$ is the gas constant, and $T$ is the absolute temperature. Substituting Eqn. (4) into Eqn. (3) gives

$\frac{d \alpha}{d t}=A \exp \left(-\frac{E}{R T}\right) \cdot f(\alpha)$

Considering a constant heating rate of $\beta=\frac{d T}{d t}$, Eqn. (5) can be rearranged to

$\frac{d \alpha}{d T}=\frac{A}{\beta} \exp \left(-\frac{E}{R T}\right) \cdot f(\alpha)$

Coats-Redfern (CR) method employs the integral form of Eqn. (6), as presented in Eqn. (7).

$g(\alpha)=\int_{0}^{\alpha} \frac{d \alpha}{f(\alpha)}=\frac{A}{\beta} \int_{T_{0}}^{T} \exp \left(\frac{-E}{R T}\right) d T$

where $g(\alpha)$ is the integrated form of the conversion dependence function $f(\alpha)$. CR method is further integrated, yielding:

$\operatorname{In}\left[\frac{g(\alpha)}{T^{2}}\right]=\operatorname{In}\left[\frac{A R}{\beta E}\left(1-\frac{2 R T}{E}\right)\right]-\frac{\mathrm{E}}{R T}$

As the temperature range applied in the combustion of the samples, the value of $\frac{2 R T}{E}$ was far less than one, so Eq. (9) is obtained.

In $\left[\frac{g(\alpha)}{T^{2}}\right]=\operatorname{In}\left(\frac{A R}{\beta E}\right)-\frac{E}{R T}$

where, $\ln \frac{A R}{\beta E}$ is essentially a constant value.

A straight line should be obtained from the plotting of In $\left[\frac{g(\alpha)}{T^{2}}\right]$ against $\frac{1}{T}$ as they have a linear relationship. If the correct $\mathrm{g}(\alpha)$ is used, the straight line should have a high correlation coefficient of linear regression analysis. Then, the values of $\mathrm{E}$ and $\mathrm{A}$ can be derived from the slope $-\frac{E}{R}$ and the intercept In $\left(\frac{A R}{\beta E}\right)$, respectively [7]. By identifying $\mathrm{g}(\alpha)$ that gives the highest correlation coefficient, the pyrolysis reaction of the samples can be associated with the appropriate mechanisms. Table 2 shows the basic model functions that were used in this kinetic study of solid-state reactions.

Table 2: Expressions of functions $g(\alpha)$ and their corresponding mechanisms (Adapted from Vlaev et al., 2008; Gil et al., 2010)

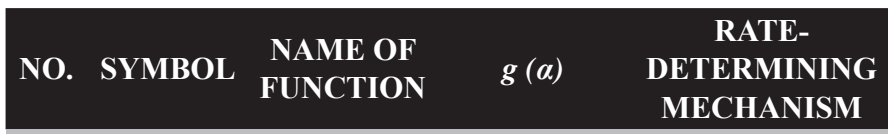

1. Chemical process or mechanism non-invoking equations

\begin{tabular}{|cclcc|}
\hline 1.1 & $F_{1 / 3}$ & $\begin{array}{l}\text { One-third } \\
\text { order }\end{array}$ & $1-(1-\alpha)^{2 / 3}$ & Chemical reaction \\
\hline 1.2 & $F_{3 / 4}$ & $\begin{array}{l}\text { Three- } \\
\text { quarters } \\
\text { order }\end{array}$ & $1-(1-\alpha)^{1 / 4}$ & Chemical reaction \\
\hline 1.3 & $F_{3 / 2}$ & $\begin{array}{l}\text { One and a } \\
\text { half order }\end{array}$ & $(1-\alpha)^{-1 / 2}-1$ & Chemical reaction \\
\hline 1.4 & $F_{1}$ & First Order & $-1 \mathrm{n}(1-\alpha)$ & Chemical reaction \\
\hline
\end{tabular}




\section{YEN YEE CHONGa, SUCHITHRA THANGALAZHY-GOPAKUMAR ${ }^{\mathrm{a}, ~}$,}

SUYIN GAN ${ }^{\text {a }}$, HOON KIAT NG ${ }^{b}$, LAI YEE LEE ${ }^{a}$

\begin{tabular}{|c|c|c|c|c|}
\hline 1.5 & $F_{2}$ & $\begin{array}{l}\text { Second } \\
\text { Order }\end{array}$ & $(1-\alpha)^{-1}-1$ & Chemical reaction \\
\hline 1.6 & $F_{3}$ & Third Order & $(1-\alpha)^{-2}-1$ & Chemical reaction \\
\hline \multicolumn{5}{|c|}{ 2. Phase boundary reaction } \\
\hline 2.1 & $R_{1}, F_{0}, P_{1}$ & Power law & $\alpha$ & Contracting disk \\
\hline 2.2 & $R_{2}, F_{1 / 2}$ & Power law & $1-(1-\alpha)^{1 / 2}$ & $\begin{array}{l}\text { Contracting } \\
\text { cylinder }\end{array}$ \\
\hline 2.3 & $R_{3}, F_{2 / 3}$ & Power law & $1-(1-\alpha)^{1 / 3}$ & Contracting sphere \\
\hline \multicolumn{5}{|c|}{ 3. Based on the diffusion mechanism } \\
\hline 3.1 & $D_{1}$ & Parabola low & $\alpha^{2}$ & $\begin{array}{l}\text { One-dimensional } \\
\text { diffusion }\end{array}$ \\
\hline 3.2 & $D_{2}$ & $\begin{array}{l}\text { Valensi } \\
\text { equation }\end{array}$ & $\begin{array}{l}\alpha+(1-\alpha) \\
\ln (1-\alpha)\end{array}$ & $\begin{array}{l}\text { Two-dimensional } \\
\text { diffusion }\end{array}$ \\
\hline 3.3 & $D_{3}$ & $\begin{array}{l}\text { Jander } \\
\text { equation }\end{array}$ & {$\left[1-(1-\alpha)^{1 / 3}\right]^{2}$} & $\begin{array}{l}\text { Three-dimensional } \\
\text { diffusion, spherical } \\
\text { symmetry }\end{array}$ \\
\hline 3.4 & $D_{4}$ & $\begin{array}{l}\text { Ginstling- } \\
\text { Brounstein } \\
\text { equation }\end{array}$ & $\begin{array}{l}{\left[1-\frac{2 \alpha}{3}-\right.} \\
(1-\alpha)^{2 / 3}\end{array}$ & $\begin{array}{l}\text { Three-dimensional } \\
\text { diffusion, } \\
\text { cylindrical } \\
\text { symmetry }\end{array}$ \\
\hline 3.5 & $D_{5}$ & $\begin{array}{l}\text { Zhuravlev, } \\
\text { Lasokin, } \\
\text { Tempelman } \\
\text { equation }\end{array}$ & {$\left[(1-\alpha)-\frac{1}{3}-1\right]^{2}$} & $\begin{array}{l}\text { Three-dimensional } \\
\text { diffusion }\end{array}$ \\
\hline 3.6 & $D_{6}$ & $\begin{array}{l}\text { anti-Jander } \\
\text { equation }\end{array}$ & {$\left[(1+\alpha) \frac{1}{3}-1\right]^{2}$} & $\begin{array}{l}\text { Three-dimensional } \\
\text { diffusion }\end{array}$ \\
\hline 3.7 & $D_{7}$ & $\begin{array}{l}\text { anti- } \\
\text { Ginstling- } \\
\text { Brounstein } \\
\text { equation }\end{array}$ & $\begin{array}{l}1+\frac{2 \alpha}{3}- \\
(1+\alpha)^{2 / 3}\end{array}$ & $\begin{array}{l}\text { Three-dimensional } \\
\text { diffusion }\end{array}$ \\
\hline 3.8 & $D_{8}$ & $\begin{array}{l}\text { anti- } \\
\text { Zhuravlev, } \\
\text { Lasokin, } \\
\text { Tempelman } \\
\text { equation }\end{array}$ & {$\left[(1+\alpha)-\frac{1}{3}-1\right]^{2}$} & $\begin{array}{l}\text { Three-dimensional } \\
\text { diffusion }\end{array}$ \\
\hline
\end{tabular}

\subsection{RESULTS AND DISCUSSION}

\subsection{Synergic Effect}

Figure 1 depicts the TG and DTG curves of EFB, POME sludge, and their blends at a heating rate of $20^{\circ} \mathrm{C} / \mathrm{min}$ in the presence of $\mathrm{N}_{2}$. With the increase of sludge percentages in the blends, the profiles of both the TG and DTG curves shifted from EFB to sludge where combustion reactivity gradually decreased.

The understanding of synergic effect in the production of biooil via co-pyrolysis is important as it is one of the main factors responsible in the measuring or determining improvements in oil quality and quantity [10]. Positive or negative synergic effect relies on the type and contact between the components, duration of pyrolysis, temperature and heating rate, removal or equilibrium of volatiles formed, and addition of solvents, catalysts, and hydrogen donors [10].

In order to investigate the interaction between EFB and POME sludge, the theoretical and experimental values of blends during co-pyrolysis were compared to and presented in Figure 1. Experimental values showed higher mass loss as compared to those of theoretical values, suggesting that more cellulose and hemicellulose were being degraded than expected. This finding hinted the existence of interaction between EFB and POME sludge, known as the synergistic effect [11]. Zhang et al., obtained a positive synergic effect in the co-pyrolysis of legume straw and coal [12]. In that study, the biomass was considered as hydrogen donor, which aided the hydrogenation of coal upon pyrolysis, resulting in some positive synergies.

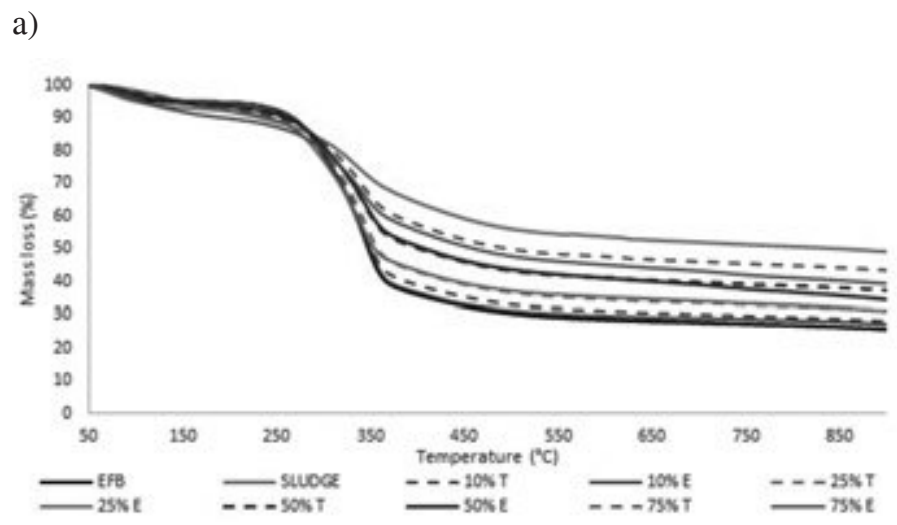

b)

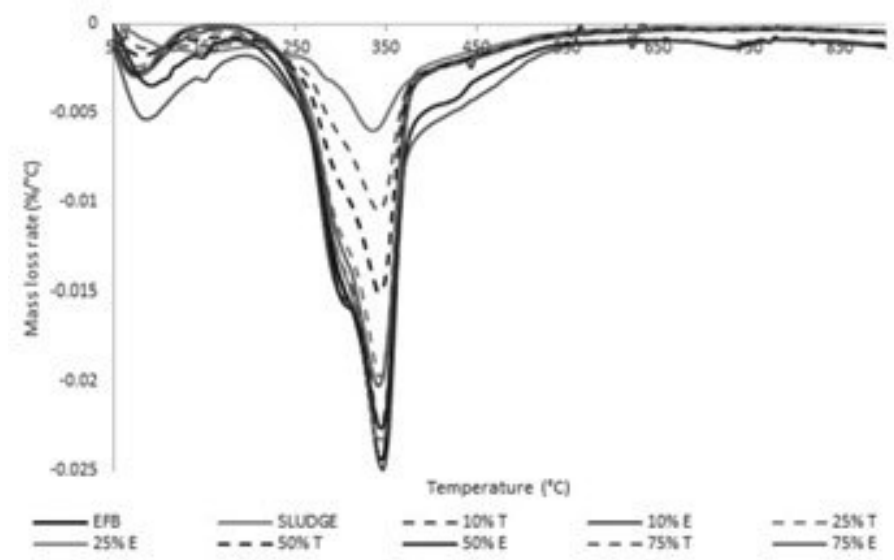

Figure 1: (a) TG curves and (b) DTG curves of EFB, POME sludge, and their blends at $\beta=20^{\circ} \mathrm{C} / \mathrm{min}$.

\subsection{Kinetics and Mechanisms of Co-pyrolysis by Coats-Redfern (CR) Method}

Using Coats and Redfern (CR) method, the solid-state mechanisms involved in the pyrolysis of EFB, POME sludge, and their blends were determined to guide and optimize production. Based on the mechanisms that gave the highest correlation coefficient $\left(\mathrm{R}^{2}\right)$, the kinetic triplets $(\mathrm{E}, \mathrm{A}$, and $\mathrm{f}(\mathrm{x}))$ of the stages were calculated and identified.

Based on TGA results as presented in Table 3, the samples were divided to three different stages and analysed separately. Stage 1 ranges from 40 to $200^{\circ} \mathrm{C}$; Stage 2 from 200 to $400^{\circ} \mathrm{C}$; and Stage 3 from 400 to $650^{\circ} \mathrm{C}$. The highest correlations ranged between $0.9774-0.9992$, indicating the reliability of the kinetic parameters obtained.

Table 3: Kinetic parameters for $\mathrm{EFB}$, POME sludge, and their blends at a heating rate of $20^{\circ} \mathrm{C} / \mathrm{min}$

\begin{tabular}{|c|c|c|c|c|c|}
\hline Stages & $\begin{array}{c}\text { Sample } \\
\text { (EFB : POME } \\
\text { sludge) }\end{array}$ & E (kJ/mol) & A, (1/s) & $\begin{array}{c}\text { Kinetic } \\
\text { Model }\end{array}$ & $\mathrm{R}^{2}$ \\
\hline 1 & $100: 0$ & 116465.31 & $1.40 \times 10^{18}$ & $\mathrm{~F} 3$ & 0.9910 \\
\hline & $90: 10$ & 96486.29 & $7.21 \times 10^{14}$ & $\mathrm{~F} 3$ & 0.9968 \\
\hline & $75: 25$ & 91946.74 & $1.44 \times 10^{14}$ & $\mathrm{~F} 3$ & 0.9948 \\
\hline
\end{tabular}




\begin{tabular}{|c|c|c|c|c|c|}
\hline & $50: 50$ & 80956.20 & $1.02 \times 10^{12}$ & F3 & 0.9882 \\
\hline & $25: 75$ & 70726.41 & $2.32 \times 10^{10}$ & F3 & 0.9795 \\
\hline & $0: 100$ & 66627.50 & $1.51 \times 10^{9}$ & $\mathrm{~F} 3$ & 0.9467 \\
\hline \multirow[t]{15}{*}{2} & $100: 0$ & 89327.76 & $2.77 \times 10^{7}$ & F1 & 0.9986 \\
\hline & & 79405.60 & $9.29 \times 10^{5}$ & $\mathrm{R} 3$ & 0.9972 \\
\hline & & 168487.26 & $2.41 \times 10^{13}$ & D3 & 0.9976 \\
\hline & $90: 10$ & 81203.96 & $4.25 \times 10^{6}$ & F1 & 0.9914 \\
\hline & & 194161.51 & $7.63 \times 10^{15}$ & D5 & 0.9972 \\
\hline & $75: 25$ & 81272.14 & $4.43 \times 10^{6}$ & F1 & 0.9970 \\
\hline & & 193804.00 & $7.50 \times 10^{15}$ & D5 & 0.9971 \\
\hline & $50: 50$ & 74111.12 & $1.03 \times 10^{6}$ & F1 & 0.9992 \\
\hline & & 65676.36 & $4.65 \times 10^{4}$ & R3 & 0.9961 \\
\hline & & 141008.83 & $7.36 \times 10^{10}$ & D3 & 0.9968 \\
\hline & $25: 75$ & 68966.29 & $3.25 \times 10^{5}$ & F1 & 0.9990 \\
\hline & & 61002.95 & $1.62 \times 10^{4}$ & $\mathrm{R} 3$ & 0.9940 \\
\hline & & 131688.61 & $9.77 \times 10^{9}$ & D3 & 0.9952 \\
\hline & $0: 100$ & 63473.91 & $8.39 \times 10^{4}$ & F1 & 0.9967 \\
\hline & & 154203.47 & $1.53 \times 10^{12}$ & D5 & 0.9987 \\
\hline \multirow[t]{6}{*}{3} & $100: 0$ & 167905.27 & $1.55 \times 10^{12}$ & F3 & 0.9836 \\
\hline & $90: 10$ & 202126.52 & $1.32 \times 10^{14}$ & F3 & 0.9785 \\
\hline & $75: 25$ & 176801.46 & $2.64 \times 10^{12}$ & F3 & 0.9753 \\
\hline & $50: 50$ & 173550.61 & $3.46 \times 10^{12}$ & F3 & 0.9774 \\
\hline & $25: 75$ & 169509.91 & $1.25 \times 10^{12}$ & F3 & 0.9971 \\
\hline & $0: 100$ & 211313.71 & $1.39 \times 10^{15}$ & F3 & 0.9790 \\
\hline
\end{tabular}

Stage 1 mainly involved the dewatering of samples, where the third order chemical reaction model (F3) was in dominion. The exceptions to this model are EFB : POME sludge of $25: 75$ and $0: 100$, which have higher correlation coefficients attributed to second order (F2) and one and a half order (F3/2), respectively. A lower rate of reaction for the two exceptions might be caused by the volatilizing of other small percentage components that was present in POME sludge. At this stage, the rate determining step was the chemical reaction, mostly dehydration reaction.

Hemicellulose and cellulose devolatilizes at Stage 2, which was the main decomposition stage of the samples. At this stage, many reactions were involved, such as devolatilization, cracking, hydration, and carbonization. Therefore, it was obvious that mass transfer had a dominant role in rate determination in addition to reaction. In Stage 2, the solid-state reaction followed first order kinetic (F1), and three dimensional diffusion mechanisms, either Jander equation (D3) or Zhuravlev, Lasokin, Tempelman equation (D5). Jander equation (D3) is for reactions in a sphere, where diffusion in all three directions is equally important [13]. On the other hand, Zhuravlev, Lesokin, Tempelman equation (D5) does not reveal the shape of the particle. Phase boundary mechanism or power law (R3) was dominant for EFB pyrolysis and in some co-pyrolysis ratios. Power law in phase boundary reaction (R3) is a reaction controlled by movement of an interface at constant velocity and at which nucleation occurs virtually immediately, so that the surface of each particle is covered with a layer of the product. This function is usually assumed to be the governing conversion model in the combustion of certain carbonaceous materials [13]. The rate determining mechanism for first order kinetic (F1) is the chemical reaction, where there was an equal probability of nucleation at each active site [13].
Both power law (R3) and Jander (D3) mechanisms involve reaction for spherical symmetries, suggesting the presence of spherical particles in the samples. Since both of these kinetic models were attributed to EFB but not POME sludge, it can be concluded that the sphere particles were contributed by EFB. Similar results were obtained by Liu et al., in the study of the decomposition of wood and leaf of fir plants, which gave good linearity for first order reaction (F1), Jander equation (D3), and power law in phase boundary reaction (R3) [14].

For stage 3, devolatilization of lignin occurred for all samples and the model obtained was the third order kinetic model (F3). Employing Coats-Redfern method, $\mathrm{Bu}$ et al., concluded that second order reaction mechanism (F2) fits well for raw alkali lignin pyrolysis with $\mathrm{R}^{2}$ of 0.9970 . However, third order reaction mechanism also showed a good $\mathrm{R}^{2}$ of 0.9960 [15].

According to Yorulmaz and Atimtay, the fact that thermal analysis allows the fitting of more than one kinetic model to the samples is not favourable and was noticed in this study [16]. Thus, combining TGA including dynamic and isothermal studies could be used to obtain the exact mechanisms and thermal constants of the oxidation process. In the current study, third order (F3) mechanism was assumed to be the main mechanism responsible for the oxidation of samples in both Stage 1 and Stage 3. As for Stage 2, first order reaction (F1) is seen as the main mechanism, accompanied by power law (R3) and Jander equation (D3) or Zhuravlev, Lasokin, Tempelman equation (D5) mechanisms.

As observed from the Table 3, activation energies for the Stage 1 decreased with the increase in POME sludge percentages. The alkaline earth metals in sludge ash might have acted as catalyst and reduced the activation energy for volatilization. Besides that, the amount of volatiles decreases with the increase of POME sludge percentages, which in turn lowered the activation energy of the sample.

As the percentages of POME sludge increased in the sample, the temperature at which the main decomposition stage (Stage 2) started decomposing increased. This finding had been obtained by $\mathrm{Mu}$ et al., [4]. It was explained that the percentage of volatiles in the samples played a role in contributing to the activation energy, where the activation energy increases with the increase in volatile percentage. As observed in Figure 1, both TG and DTG curves showed that the devolatilization stage of EFB is indeed much steeper than that of POME sludge, indicating the much higher volatile percentage in EFB.

As compared to other stages, Stage 3 that mainly involves the devolatilization of lignin showed the highest activation energy. The activation energy obtained was $183.53 \pm 18.46 \mathrm{~kJ} /$ $m o l$. Decomposition of lignin required higher activation energy than other components as lignin has a more complicated structure and higher molecular weight. Besides that, char that formed in Stage 2 may have contributed to the higher activation energy due to secondary cracking.

\section{CONCLUSION}

EFB showed higher reactivity regarding the higher mass loss rate as compared to that of POME sludge in thermogravemetric studies. Upon co-pyrolysis conducted, a positive synergistic effect (higher reactivity) was observed in the experiments than theoretical analysis. The mechanisms involved in the pyrolysis of EFB, POME sludge, and their blends were determined using 


\section{YEN YEE CHONG ${ }^{\text {a }}$, SUCHITHRA THANGALAZHY-GOPAKUMAR ${ }^{\text {a, }, \text {, }}$ SUYIN GAN ${ }^{\mathrm{a}}$, HOON KIAT NG ${ }^{\mathrm{b}}$, LAI YEE LEE ${ }^{\mathrm{a}}$}

Coats-Redfern method. For Stage 1, the dominant kinetic model was the third order reaction (F3); for Stage 2, were first order reaction (F1), power law in phase boundary reaction (R3), and Jander equation (D3) or Zhuravlev, Lasokin, Tempelman equation (D5); for Stage 3, was third order reaction (F3). Activation energies for each stage were also analysed and it can be concluded that Stage 3 showed the highest activation energy, with an average value of $183.53 \pm 18.46 \mathrm{~kJ} / \mathrm{mol}$.

\section{ACKNOWLEDGEMENT}

The authors would like to express sincere gratitude to Ministry of Higher Education for the realization of this research project under the Grant FRGS/1/2015/TK02/UNIM/02/1. However, only the authors are responsible for the opinion expressed in this paper and for any remaining errors.

\section{REFERENCES}

[1] S. H. Shuit, K. T. Tan, K. T. Lee, and A. H. Kamaruddin, "Oil palm biomass as a sustainable energy source: A Malaysian case study," Energy, vol. 34, no. 9, pp. 1225-1235, 2009.

[2] N. Abdullah, F. Sulaiman, and H. Gerhauser, "Characterisation of oil palm empty fruit bunches for fuel application," J. Phys. Sci., vol. 22, no. 1, pp. 1-24, 2011.

[3] S. Thangalazhy-Gopakumar, W. M. A. Al-Nadheri, D. Jegarajan, J. N. Sahu, N. M. Mubarak, and S. Nizamuddin, "Utilization of palm oil sludge through pyrolysis for bio-oil and bio-char production," Bioresour. Technol., vol. 178, pp. 65-69, 2015.

[4] L. Mu, J. Chen, P. Yao, D. Zhou, L. Zhao, and H. Yin, "Evaluation of co-pyrolysis petrochemical wastewater sludge with lignite in a thermogravimetric analyzer and a packed-bed reactor: Pyrolysis characteristics, kinetics, and products analysis," Bioresour. Technol., vol. 221, pp. 147-156, 2016.

[5] Y. Lin, X. Ma, Z. Yu, and Y. Cao, "Investigation on thermochemical behavior of co-pyrolysis between oil-palm solid wastes and paper sludge," Bioresour. Technol., vol. 166, pp. 444450, 2014.

[6] X. Zhu et al., "Co-pyrolysis behaviors and kinetics of sewage sludge and pine sawdust blends under non-isothermal conditions,"
J. Therm. Anal. Calorim., vol. 119, no. 3, pp. 2269-2279, Mar. 2015.

[7] L. Zhou, Y. Wang, Q. Huang, and J. Cai, "Thermogravimetric characteristics and kinetic of plastic and biomass blends copyrolysis," Fuel Process. Technol., vol. 87, no. 11, pp. 963-969, 2006.

[8] L. Vlaev, N. Nedelchev, K. Gyurova, and M. Zagorcheva, "A comparative study of non-isothermal kinetics of decomposition of calcium oxalate monohydrate," J. Anal. Appl. Pyrolysis, vol. 81, no. 2, pp. 253-262, 2008.

[9] M. V. Gil, D. Casal, C. Pevida, J. J. Pis, and F. Rubiera, "Thermal behaviour and kinetics of coal/biomass blends during cocombustion," Bioresour. Technol., vol. 101, no. 14, pp. 56015608,2010 .

[10] F. Abnisa, W. Mohd, and A. W. Daud, "A review on co-pyrolysis of biomass: An optional technique to obtain a high-grade pyrolysis oil," Energy Convers. Manag., vol. 87, pp. 71-85, 2014.

[11] C. Quan, S. Xu, Y. An, and X. Liu, "Co-pyrolysis of biomass and coal blend by TG and in a free fall reactor," J. Therm. Anal. Calorim., vol. 117, no. 2, pp. 817-823, Aug. 2014.

[12] L. Zhang, S. Xu, W. Zhao, and S. Liu, "Co-pyrolysis of biomass and coal in a free fall reactor," Fuel, vol. 86, no. 3, pp. 353-359, 2007.

[13] S. . Alshehri, M. A. . Monshi, N. . Abd El-Salam, and R. Mahfouz, "Kinetics of the thermal decomposition of $\gamma$-irradiated cobaltous acetate," Thermochim. Acta, vol. 363, no. 1, pp. 61-70, 2000 .

[14] N. A. Liu, W. Fan, R. Dobashi, and L. Huang, "Kinetic modeling of thermal decomposition of natural cellulosic materials in air atmosphere," J. Anal. Appl. Pyrolysis, vol. 63, no. 2, pp. 303325, 2002.

[15] Q. Bu, H. Lei, M. Qian, and G. Yadavalli, "A thermal behavior and kinetics study of the catalytic pyrolysis of lignin," RSC Adv., vol. 6, no. 103, pp. 100700-100707, 2016.

[16] S. Y. Yorulmaz and A. T. Atimtay, "Investigation of combustion kinetics of treated and untreated waste wood samples with thermogravimetric analysis," Fuel Process. Technol., vol. 90, no. 7, pp. 939-946, 2009.

\section{PROFILES}

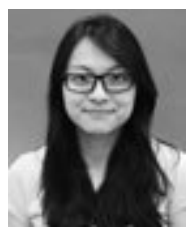

CHONG YEN YEE is currently a PhD student in University of Nottingham, Malaysia. She received her MEng (Hons) in Chemical and Environmental Engineering from the same university in 2015. Chong's research aims to improve the qualities of bio-crude oil (bio-oil) that is produced from empty fruit bunches. The bio-oil derived from empty fruit bunches is acidic whereas bio-oil derived from palm oil mill effluent sludge is alkaline in nature. Thus, combining both these biomass as feed may produce a bio-oil that has a pH similar to crude oil. Email: kebx6cyy @ nottingham.edu.my.

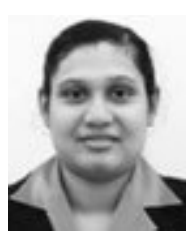

DR SUCHITHRA THANGALAZHY GOPAKUMAR is an Assistant Professor in the Department of Chemical and Environmental Engineering, University of Nottingham Malaysia Campus. Dr Suchithra received her Doctoral degree in Chemical Engineering from Auburn University, Alabama, USA. Her Masters degree is in Chemical Engineering (specialization: Industrial Pollution Control) from National Institute of Technology Karnataka, Surathkal, India, and Bachelors degree in Chemical Engineering from Government Engineering College Thrissur, Kerala, India. Dr Suchithra's research focus on the development of liquid biofuels from various biomass feedstocks through thermo-chemical conversions and catalytic upgrading. Email: Suchithra.Thangalazhy@ nottingham.edu.my. 


\section{SYNERGIC EFFECT AND KINETIC MECHANISMS FOR CO-PYROLYSIS OF EMPTY FRUIT BUNCH AND PALM OIL SLUDGE}

DR GAN SUYIN is currently a Professor of Chemical Engineering at the Department of Chemical and Environmental Engineering, University of Nottingham Malaysia Campus. Prof. Gan works in a wide range of interdisciplinary experimental and computational activities within the central theme of energy and fuels. This includes biofuel processing technologies, combustion cum emissions characterisation, cleaner combustion systems applications as well as in-situ emission mitigation strategies and environmental pollutant abatement. She has over 90 publications to date in internationally refereed journals, technical papers, congress/conference proceedings and book chapters. She has led a number of projects which are funded by government organisations, industry and university and has established collaborations with various local and international partners. She also serves on the editorial board of two international journals. Email: suyin.gan@nottingham.edu.my.

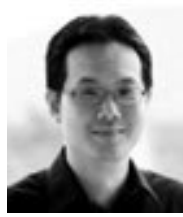

DR NG HOON KIAT is Professor of Mechanical Engineering in the Department of Mechanical, Materials and Manufacturing Engineering, University of Nottingham Malaysia Campus. He served as the head of the Energy, Fuel and Power Technology research division, academic champion of the aerospace priority area and the founding deputy director of the Asia Aerospace City Research and Technology Centre. He is currently the head of the department and the campus academic champion for the energy research priority area.

Prof. $\mathrm{Ng}$ works in a wide range of interdisciplinary experimental and computational projects, including chemical kinetics modelling of diesel/ biodiesel combustion, biofuels production and combustion, engine testing, parallel processing and neural network analysis of engine performance/ emissions, as well soil remediation using extraction and advanced oxidation processes (AOP). He has well over 140 publications to date in internationally refereed journals, technical papers, congress/conference proceedings, book chapters and books. He also serves on the editorial board of international journals, and have been appointed to various advisory panels and expert committees. He has led a number of projects which are funded from diverse sources including government organisation, industry and university. Additionally, he has also established long-term collaborations with both industrial and academic partners in Europe and Asia. Email: hoonkiat.ng@nottingham.edu.my.

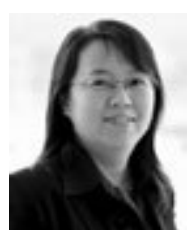

DR LEE LAI YEE is currently an Associate Professor at the Department of Chemical and Environmental Engineering, University of Nottingham Malaysia Campus. Dr Lee obtained her Bachelor and PhD degrees in Chemical Engineering from the University of Bath, United Kingdom. Her PhD research work involved volatile organic compounds (VOCs) adsorption onto low-pressure drop silicalite monoliths. She has established research in the field of water and wastewater treatment, thermochemical conversion of biomass and application of agricultural waste as value added products at UNMC. Her current research work focuses on the development of adsorbing materials and nanomaterials for environmental pollution control and product recovery from industrial effluent. Her research work also involves nanoporous material fabrication for energy storage. Email: lai-yee. lee@nottingham.edu.my. 